\title{
VARIABILIDADE GENÉTICA E FILOGENIA DO PAPILOMAVÍRUS HUMANO TIPO 58 NO NORDESTE BRASILEIRO
}

\author{
B. S. CHAGAS ${ }^{1}$, A. C. M. RIOS ${ }^{1}$, R. C. O. SILVA ${ }^{1}$, E. TIBÚRCIO Jr ${ }^{1}$, R. C. P. LIMA ${ }^{1}$, M. \\ N. CORDEIRO ${ }^{1}$, D. L. SANTOS ${ }^{1}$, T. S. P. C. NEVES ${ }^{1}$, A. H. P. SILVA Jr ${ }^{1}$, A. P. A. D. \\ GURGEL $^{2}$, M. R. BARROS Jr ${ }^{1}$, M. V. A. BATISTA ${ }^{3}$, A. C. FREITAS ${ }^{1}$ \\ ${ }^{1}$ Universidade Federal de Pernambuco, Departamento de Genética, Laboratório de Estudos \\ Moleculares e Terapia Experimental \\ ${ }^{2}$ Universidade Federal da Paraíba, Departamento de Engenharia e Meio ambiente \\ ${ }^{3}$ Universidade Federal de Sergipe, Departamento de Biologia
}

E-mail para contato: babisimas@gmail.com; carinemirandar@gmail.com; acf_ufpe@yahoo.com.br

RESUMO - O Papilomavírus humano (HPV) é o principal fator de risco para o câncer cervical. Estudos têm demonstrado que variantes do HPV difere em sua associação com o câncer cervical. O objetivo deste estudo foi analisar a variabilidade genética e filogenia do HPV-58. Para isso, amostras de DNA positivas para HPV-58 foram amplificadas e sequenciadas quanto ao oncogene E6. A análise das sequências revelou variações não sinônimas, as quais ocasionaram alterações de aminoácidos com propriedades físicoquímicas diferentes. A árvore filogenética gerada a partir de sequências de E6 agruparam os isolados de HPV-58 em sublinhagens A2, C1 e D2.

Palavras chave: Polimorfismo, análise filogenética, oncogene E6.

ABSTRACT - Human papillomavirus (HPV) is the main risk factor for cervical cancer. Studies have shown that variants of HPV differ in their association with cervical cancer. The objective of this study was to analyze the genetic variability and phylogeny of HPV58. For this, HPV-58 positive DNA samples were amplified and sequenced for the E6 oncogene. Sequence analysis revealed non-synonymous variations, which resulted in amino acid changes with different physicochemical properties. The phylogenetic tree generated from E6 sequences grouped the HPV-58 isolates into A2, C1 and D2 sublineage.

Keywords: Polymorphism, phylogenetic analysis, E6 oncogene.

\section{INTRODUÇÃO}

O câncer cervical representa o quarto tipo de neoplasia mais frequente entre as mulheres no mundo (INCA, 2017). De acordo com a Organização Mundial da Saúde (OMS), a infecção persistente pelo Papilomavírus humano (HPV) é o principal fator de risco para o desenvolvimento de câncer cervical (Baseman \& Koutsky, 2005). Embora o HPV-16 seja o tipo mais prevalente em todas as regiões, outros tipos virais estão apresentando uma prevalência considerável, caso dos HPVs 58 e 31 . No caso do HPV58, o mesmo tem mostrando uma significante prevalência em regiões como Distrito 
Federal, Rio Grande do Norte, Recife e Norte do País (Lorenzato et al., 2000; Baldez da Silva et al., 2009).

Estudos têm demonstrado que variantes do HPV-16 difere em sua associação com o câncer cervical (Xi et al., 1997). Mutações não sinônimas presentes no oncogene E6 podem ocasionar alterações das propriedades biológicas da proteína codificada (Zehbe et al., 2003). Considerando a prevalência do HPV-58 em mulheres da região Nordeste do Brasil, foi necessária a investigação de alterações nucleotídicas no oncogene E6 do HPV-58, uma vez que o gene E6 é responsável pela atividade transformante degradando a proteína supressora de tumor p53. Dessa forma, o objetivo deste estudo foi detectar a variabilidade genética do HPV-58 e relacionar as variações nucleotídicas não sinônimas com alterações nas propriedades físico-químicas dos aminoácidos da oncoproteína E6. Além disso, as relações filogenéticas entre os isolados do HPV58 foram analisadas.

\section{MATERIAIS E MÉTODOS}

Um total de 150 amostras coletadas no Hospital das Clínicas (Universidade Federal de Pernambuco) foi obtido através de raspagem do colo do útero com cytobrush. O DNA foi extraído a partir das células cervicais utilizando Dneasy Blood Tissue Kit (Qiagen), seguindo o protocolo do fabricante. Aprovação do Comitê de Ética (CEP/CCS/UFPE N 491/11).

A detecção de HPV foi realizada por PCR (iniciadores MY09/11) (Manos et al., 1989). A região genômica E6 do HPV-58 foi amplificada por PCR utilizando iniciadores específicos. O sequenciamento do oncogene E6 foi realizado utilizando kit ABI PRISM BigDye ${ }^{\mathrm{TM}}$ Terminator Cycle Sequencing V.3.1 (Applied Biosystems). As sequências foram analisadas utilizando o programa Staden (Staden, 1996). Sequências E6 do HPV-58 foram comparadas com as sequências do GenBank utilizando o BLAST (Altschul et al., 1990). Alinhamento múltiplo foi realizado usando ClustalW (Thompson et al., 1994). Análise filogenética foi realizada através da sequência de E6 do HPV-58, utilizando métodos baseados em Neighbor-Joining através do programa MEGA (Kumar et al., 2016).

\section{RESULTADOS E DISCUSSÃO}

Das 150 amostras cervicais, 91 amostras (60.7\%) foram positivas para HPV e dentre estas $18(19.8 \%)$ foram positivas para o HPV-58. Sequências nucleotídicas completas do oncogene E6 de quatro pacientes foram comparadas com a sequência de referência (EU918765.1). Os resultados da variabilidade encontram-se na Tabela 1. Nenhuma nova mutação em E6 foi encontrada. A análise das propriedades dos aminoácidos foi realizada e foram observadas alterações na polaridade, carga de cadeia lateral e índice hidrópatico em E6 do HPV-58 conforme mostra na Tabela 2. Esse tipo de mudança geralmente está relacionado à alteração na estrutura conformacional das proteínas, o que pode levar a uma alteração funcional.

Tabela 1 - Variabilidade genética da região E6 do HPV-58. Referência: sequência protótipo do HPV-58 (EU918765.1). 
Tabela 2 - Propriedades dos aminoácidos alterados por substituições nucleotídicas em

\begin{tabular}{lccccccccc}
\hline Nucleotídeos & 187 & 245 & 246 & 307 & 365 & 367 & 392 & 398 & 400 \\
\hline Referência & $\mathrm{C}$ & $\mathrm{G}$ & $\mathrm{T}$ & $\mathrm{C}$ & $\mathrm{G}$ & $\mathrm{C}$ & $\mathrm{T}$ & $\mathrm{A}$ & $\mathrm{T}$ \\
\hline Isolado 58SE & $\mathrm{T}$ &. &. & $\mathrm{T}$ &. & $\mathrm{A}$ &. &. &. \\
Isolado 30SE &. &. &. & $\mathrm{T}$ &. &. &. &. &. \\
Isolado 60M &. & $\mathrm{A}$ & $\mathrm{C}$ & $\mathrm{T}$ & $\mathrm{A}$ & & $\mathrm{C}$ & $\mathrm{G}$ & $\mathrm{G}$ \\
Isolado 59M &. &. &. & $\mathrm{T}$ &. &. &. &. &. \\
\hline Referência & $\mathrm{I}$ & $\mathrm{V}$ & $\mathrm{C}$ & $\mathrm{D}$ & $\mathrm{D}$ & $\mathrm{C}$ & & $\mathrm{N}$ \\
Posição do aminoácido alterado & 26 & 46 & 66 & 86 & 86 & 95 & 97 \\
Aminoácido alterado & $\mathrm{I}$ & $\mathrm{T}$ & $\mathrm{C}$ & $\mathrm{N}$ & $\mathrm{E}$ & $\mathrm{R}$ & & $\mathrm{E}$ \\
\hline
\end{tabular}

E6 HPV-58. A carga da cadeia lateral dos aminoácidos não ionizados está marcada com asterísticos $(*)$. (-), carga da cadeia lateral dos aminoácidos ionizados negativamente.

\begin{tabular}{lcccc}
\hline Isolados & Polimorfismos & \multicolumn{3}{c}{ Propriedades dos aminoácidos } \\
\hline & & Polaridade & $\begin{array}{c}\text { Carga de } \\
\text { cadeia } \\
\text { lateral }\end{array}$ & Índice Hidropático \\
\hline Isolado 58SE & $\mathrm{D} / \mathrm{E}$ & Polar/Polar & $-/-$ & Hidrofílico/Hidrofílico \\
\hline Isolado 60M & $\mathrm{V} / \mathrm{T}$ & Apolar/Polar & $* /-$ & Hidrofóbico/Hidrofílico \\
& $\mathrm{D} / \mathrm{N}$ & Polar/Polar & $-/ *$ & Hidrofílico/Hidrofílico \\
& $\mathrm{C} / \mathrm{R}$ & Polar/Polar & $-/+$ & Hidrofóbico/Hidrofílico \\
& $\mathrm{N} / \mathrm{E}$ & Polar/Polar & $* /-$ & Hidrofílico/Hidrofílico \\
\hline
\end{tabular}

Quanto à análise filogenética, a árvore filogenética gerada a partir de sequências de E6 agruparam os isolados de HPV-58 em três principais grupos chamados sublinhagens A2, C1 e D2 (Figura 1).

Figura 1 - Arvore filogenética de variantes HPV-58 baseada em sequências do oncogene E6.

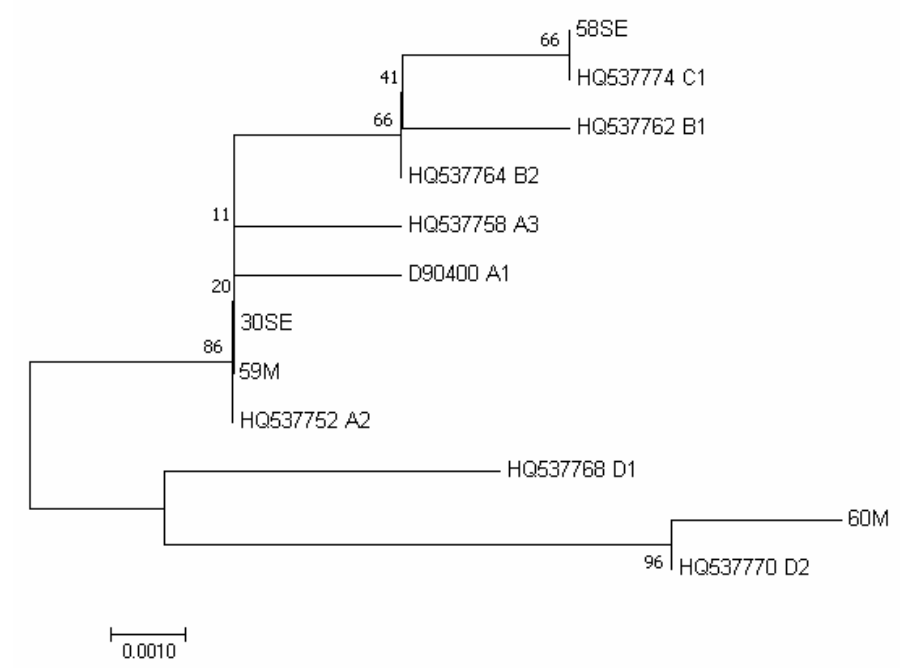

\section{CONCLUSÃO}


O presente estudo apresenta alterações nucleotídicas não conservativas detectadas no oncogene E6 do HPV-58 e sugere a possibilidade disto provocar alterações estruturais nas proteínas e consequentemente alterações funcionais, as quais causariam impacto na tumorigênese, através do aumento do potencial oncogênico do HPV. Além disso, o entendimento da diversidade genética de HPV de alto risco é relevante para confecção da vacina.

\section{REFERÊNCIAS}

ALTSCHUL, S.F.; GISH, W. Basic local alignment search tool. J. Mol. Biol., v. 215, p. 403-410, 1990.

BALDEZ DA SILVA, M.F.; CHAGAS, B.S.; GUIMARÃES, V.; KATZ, L.M.C.; FELIX, P.M.; MIRANDA, P.M.; LIMA, A.A.; ARRAES, L.C.; MARTINS, D.B.G.; LIMA FILHO, J.L. HPV31 and HPV33 incidence in cervical samples from women in Recife, Brazil. Genet. Mol. Res., v. 8, p. 1437-1443, 2009.

BASEMAN, J.G.; KOUTSKY, L.A. The epidemiology of human papillomavirus infections. J. Clin. Virol., v. 32S, p. S16-S24, 2005.

INSTITUTO NACIONAL DO CÂNCER (INCA), 2017. Diretrizes brasileiras para o rastreamento do câncer do colo do útero, Rio de Janeiro, Ministério da Saúde, Brasil.

http://www.inca.gov.br/estimativa/2016/estimati va-2016-v11.pdf (25 de novembro de 2017).

KUMAR, S.; STECHER, G.; TAMURA, K. MEGA7:Molecular Evolutionary Genetics Analysis Version 7.0 for Bigger Datasets. Mol. Biol. Evol., v. 33, p. 1870-1874, 2016.

LORENZATO, F.; HO, L.; TERRY, G.; SINGERS, A.; SANTOS, L.C. The use of human papillomavirus typing in detection of cervical neoplasia in Recife (Brazil). Int J Gynecol Cancer, v. 10, p. 143-150, 2000.

MANOS, M.M.; TING, Y. The use of polymerase chain reaction amplification for the detection of genital human papillomavirus. Cancer Cells, v. 7, p. 209-214, 1989.

Staden, R. The Staden Sequence Analysis Package. Mol Biotech. v. 5, p. 233-241, 1996. THOMPSON, J.D., HIGGINS, D.G., GIBSON, T.J. CLUSTAL W: improving the sensitivity of progressive multiple sequence alignments through sequence weighting, position specific gap penalties and weight matrix choice. Nucl. Acids. Res., v. 22, p. 4673-4680, 1994.

XI, L.F.; KOUTSKY, L.A.; GALLOWAY, D.A.; KUYPERS, J.; HUGHES, J.P.; WHEELER, C.M.; HOLMES, K.K.; KIVIAT, N.B. Genomic variation of human papillomavirus type 16 and risk for high grade cervical intraepithelial neoplasia. J Natl Cancer Inst, v. 89, p. 796-802. 1997.

ZEHBE, I.; MYTILINEOS, J.; et al. Association between human papillomavirus 16 E6 variants and human leukocyte antigen class I polymorphism in cervical cancer of Swedish women. Hum Immunol., v. 64, p. 538-542, 2003.

\section{AGRADECIMENTOS}

Conselho Nacional de Desenvolvimento Científico e Tecnológico (CNPq), Fundação de Amparo à Ciência e Tecnologia de Pernambuco (FACEPE), Coordenação de Aperfeiçoamento de Pessoal de Nível Superior (CAPES), Universidade Federal de Pernambuco (UFPE).

ÁREA DE SUBMISSÃO: BIOLOGIA MOLECULAR - BM06 